\title{
Robustness of the whole Jomon femur shaft assessed by cross-sectional geometry
}

\author{
TASUKU KIMURA ${ }^{1 *}$ \\ ${ }^{1}$ Ishikawa Prefectural Nursing University, Tsu-7-1, Nakanuma, Kahoku City, Ishikawa, 929-1212 Japan
}

Received 16 September 2004; accepted 20 April 2005

\begin{abstract}
Cross-sectional geometry of ancient Jomon femora were analyzed along the whole shaft by means of computed tomography. Comparisons were made with modern Japanese (from the same geographical area as the Jomon people) and recent Germans (of larger body size and from a geographical area distant from Japan). Jomon male femora were significantly larger than those of modern Japanese males along the whole shaft length in cross-sectional area $(A)$, polar second moment of area $(I p)$, second moment of area around the mediolateral direction (Ix), maximum second moment of area (Imax), and cross-sectional index of radii of gyration $(k x / k y)$. These parameters were about the same magnitude in the Jomon males, as in the German males whose size was large, except for the second moment of area around the anteroposterior direction (Iy), which was smaller in the Jomon bones. Female Jomon femora showed the same tendency but only at the middle part of the shaft. There were allometric correlations between bone length and the geometrical properties. In order to eliminate the influence of size, relative dimensionless properties were calculated by dividing each parameter by an analogue of length, namely $A$ was divided by maximum length squared, and Ip, Ix, Iy, Imax, and Imin were divided by the fourth power of the maximum length. The German femora of both sexes were smaller than those of the Jomon in relative area, relative $I x$, and relative $I p$. Male Jomon femora contained a large volume of bone substance and were robust against bending moments especially in the anteroposterior direction along the whole shaft when comparison was made with other modern or recent groups. These characteristics are less definitive with female bones. They were caused as a functional adaptation for sedentary gatherer-hunters.
\end{abstract}

Key words: Jomon gatherer-hunters, modern Japanese, recent Germans, long bone, bending

\section{Introduction}

Jomon people were gatherer-hunters, including fishery, in the ancient Japanese archipelago from about 13000 to 2400 years before the present. They made Jomon pottery and stone tools and dwelled in permanent or seasonal settlements. The cross-sectional geometry of their appendicular lower limb bones, namely the femur, tibia, and fibula, at mid-length was reported by the present author (Kimura and Takahashi, 1982). The index of the cross section was calculated as the ratio of the radii of gyration to the mediolateral and anteroposterior directions, or that of the square root of the second moments of area around the two directions. The ratios in all bones were significantly larger in the anteroposterior direction in the Jomon group than in the recent Japanese specimens studied for comparison. The Jomon midshaft was developed so as to be robust against bending

Collected Papers in Honor of Professor Emeritus Banri Endo: Commemoration of His Seventieth Birthday

* Corresponding author. e-mail: tkimura@ishikawa-nu.ac.jp phone: +81-76-281-8374; fax: +81-76-281-8388

Published online 29 June 2005

in J-STAGE (www.jstage.jst.go.jp) DOI: 10.1537/ase.040916 moments in the anteroposterior direction, probably moments caused by active movement of the lower limb in that direction, mainly due to running and walking. Most male Jomon femora are pilastered. Femora of females are not always pilastered viewed from the outside, but their principal axis of the mid-length cross section is concentrated in the anteroposterior direction, indicating a dense distribution of bone material in this direction (Kimura and Takahashi, 1984). By analyzing cross-sectional geometry, the same direction of robustness was seen in both sexes at mid-length of the femur, which was not always detectable from external bone countours. From these results, we can estimate aspects of the activity pattern in the daily life of the Jomon people.

Cross-sectional geometry indicates robustness of the long bone (Kimura, 1974; Bass et al., 2002). The analysis was conducted on ancient bone to which mechanical experiments were difficult to apply (Endo and Kimura, 1970). Previous reports were concerned mainly with one or two sections of the ancient long bones (Lovejoy and Trinkaus, 1980; Kimura and Takahashi, 1982, 1984, 1992; Ruff et al., 1984, 1993; Brock and Ruff, 1988; Trinkaus et al., 1994, 1998, 1999a, b, c, d; Ruff, 1995, 1999; Trinkaus and Ruff, 1996; Trinkaus, 1997, 1999a, b; Stock and Pfeiffer, 2001; Holt, 2003). The robustness of the ancient femur along the whole shaft has been reported in only a few papers, such as on the 
Pecos (Ruff and Hayes, 1983a, b), Neanderthal (Trinkaus and Ruff, 1989), and Minatogawa fossils (Kimura and Takahashi, 1992). The mechanical characteristics of the pilastered ancient femur have not been fully discussed along the whole shaft.

The present paper is concerned with the cross-sectional geometry of Jomon femora along the whole length of the shaft in comparison with modern or recent bones, with emphasis on the mechanical significance of bones.

\section{Materials and Methods}

The Jomon femora that were used in the present study were stored in the Department of Anthropology and Prehistory, The University Museum, The University of Tokyo. Because regional differences in Jomon skeleton have been reported (Kondo, 1994), samples excavated only from the Kanto district, southeast Japan near Tokyo, were used. All bones, at least according to the records, belong to the Middle to Latest Jomon period. Bones with nearly the complete head, the lesser trochanter, and condyles were selected in order to measure the maximum length and to situate them in the standard coordinates, which will be explained later. The right side was selected first. If the right side was broken or missing, then the left side was used. Eighteen males and fifteen females, consisting of sixteen right and seventeen left bones, were studied. Most of the bones were the same ones whose mid-length cross section was reported previously (Kimura and Takahashi, 1982).

Comparative specimens were femora of modern Japanese and recent Germans. The modern Japanese skeletons were stored in the University Museum, the University of Tokyo. They derive from around the end of the nineteenth century and the beginning of the twentieth century in Tokyo, the same geographical area as the Jomon sample, though there is a difference of several thousand years in time. Bones with age records were used. Individuals older than 60 years were excluded, the reason for which will be discussed later in detail. The right bones of ten males and ten females were used. As a comparative sample of a different geographical area and body size from the Jomon people, German samples were collected from the dissection room of the Anatomical Department, Medical College of Hannover (Kimura and Amtmann, 1984). The individuals died near Hannover in 1976 or 1977 . The temporal and geographical separation of the German and Jomon people is very large. The birth dates of all German individuals were known. Eight males and seven females were measured along the femoral shaft. In addition, eleven males and six females were studied only at the mid-length of the bone. In total, 19 male and 13 female Germans were used, of whom more than $80 \%$ were over 60 years of age. The right side was selected.

The samples are listed in Table 1. Bones without apparent deformation or pathological traits were selected. All bones were from adult individuals with closed epiphyseal lines.

Cross-sectional geometry of the Jomon and modern Japanese bones was figured by means of a CT-apparatus (TXS225-ACTIS, TESCO) and measured by means of a computer program (CT-Rugle). Pixel size was $0.1 \mathrm{~mm}$. Contours of the CT-figure were determined at the $50 \%$ of density between air and compact bone, the measured part of which was arbitrarily chosen as the center of bone material. Small cracks in the Jomon bones were manually filled on the CTfigures. German bones were directly cut and measured by means of a digitizer and a personal computer (Kimura and Amtmann, 1984). With the German bones, trabecular bone not connected with the compact bone at the outer margin was not included in the bone area.

The frontal plane of the femur was determined to be the plane passing through the posterior ends of the lesser trochanter and the medial and lateral condyles according to the standard of Martin (1928) (Figure 1). The present frontal plane inclined slightly further forwards than that of Ruff (Ruff and Hayes, 1982); the proximal femur was raised forward a little more than standard. A vertical line was drawn between the mid-points of the width at the upper and lower ends of the shaft. The direction of the maximum length (Martin, 1928) was approximately parallel to the vertical line in most bones. The anteroposterior plane was set as the plane parallel to the vertical line and perpendicular to the frontal plane. The horizontal plane was perpendicular to the frontal and anteroposterior planes. Cross sections were obtained parallel to the horizontal plane. The $x$-axis of the cross section was parallel to the frontal plane and the $y$-axis was parallel to the anteroposterior plane. Both axes passed through the centroid of the cross section. The cross-sectional area $(A)$, the polar second moment of area $(I p)$, and the second moments of area around the $x$ - and $y$-axes ( $I x$ and $I y$ ) were measured on each cross section. The maximum and minimum second moments of area (Imax and Imin) and cross-sectional indices were calculated. The cross-sectional indices were defined as ratios of radii of gyration of the cross-sectional area around the $x$ - and $y$-axes $(k x / k y)$ or around the principal axes $(\mathrm{kmax} / \mathrm{kmin})$, that is, the square

Table 1. Materials

\begin{tabular}{|c|c|c|c|c|c|c|c|c|}
\hline \multirow{2}{*}{$\begin{array}{c}\text { Sex } \\
\text { Group }\end{array}$} & \multicolumn{4}{|c|}{ Male } & \multicolumn{4}{|c|}{ Female } \\
\hline & Jomon & Japanese & German & & Jomon & Japanese & German & \\
\hline Level & All & All & All & $50 \%$ only & All & All & All & $50 \%$ only \\
\hline$n$ & 18 & 10 & 8 & 19 & 15 & 10 & 7 & 13 \\
\hline Age (year) & & $\begin{array}{c}36.7 \pm 10.8 \\
(54-23)\end{array}$ & $\begin{array}{l}74.7 \pm 14.7 \\
(85.1-39.5)\end{array}$ & $\begin{array}{l}70.5 \pm 15.8 \\
(87.8-36.3)\end{array}$ & & $\begin{array}{c}38.9 \pm 16.0 \\
(56.5-22)\end{array}$ & $\begin{array}{l}68.7 \pm 12.1 \\
(81.9-48.5)\end{array}$ & $\begin{array}{c}71.9 \pm 11.3 \\
(89.4-48.5)\end{array}$ \\
\hline $\begin{array}{l}\text { Maximum } \\
\text { length (mm) }\end{array}$ & $420.3 \pm 14.9$ & $396.1 \pm 17.9$ & $457.1 \pm 23.6$ & $467.3 \pm 26.7$ & $392.1 \pm 16.7$ & $387.7 \pm 20.6$ & $436.9 \pm 21.7$ & $438.9 \pm 22.5$ \\
\hline
\end{tabular}

Values are mean \pm standard deviation with ranges in parentheses. 

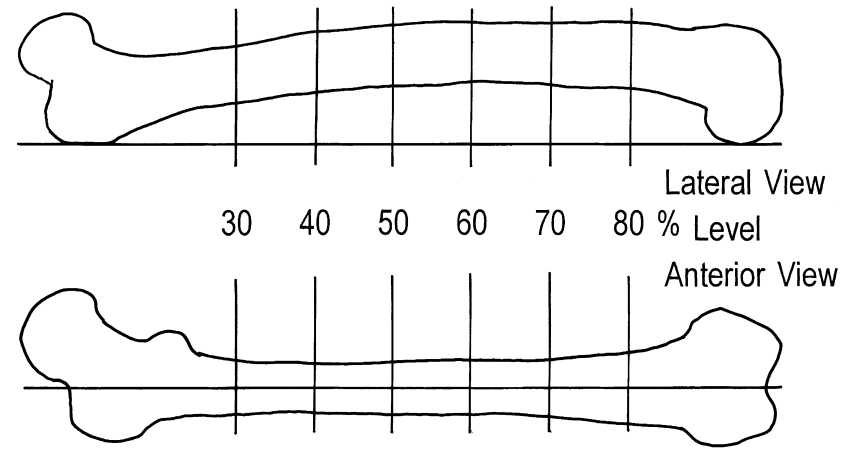

Figure 1. Levels of cross section. The six shorter lines indicate position of the cross sections. The longer lines indicate the frontal plane (lateral view) and the vertical axis (anterior view).

root of the ratio of the second moments of area (Kimura and Takahashi, 1982).

Horizontal cross sections were measured at 30, 40, 50, 60, 70 , and $80 \%$ of the maximum length from the proximal end (Figure 2). Because many German femora contained a high degree of porosity at the $80 \%$ level, it was difficult to determine the contour definitely at this level. The $80 \%$ level was deleted from the German bones. For the same reason of porosity, the $20 \%$ level was not measured in all bones. The present levels were slightly different from those used by Ruff and Trinkaus (Ruff and Hayes, 1983a; Trinkaus and Ruff, 1989). Their femoral length was the shaft length.

High correlation between the geometrical properties and the femur length have been observed (Ruff, 1984). Relative properties were calculated by dividing each parameter by an analogue of maximum length; $A$ was divided by the maximum length squared, and Ip, Ix, Iy, Imax, and Imin were divided by the fourth power of maximum length.

Differences between the averages of two groups were evaluated by the $t$-test. Slopes of reduced major axis were evaluated following Hofman (1988).

\section{Results}

Data of cross-sectional geometry are listed in Table 2 . Jomon males apparently had thicker cortical bone than modern Japanese males, as seen in Figure 2. Absolute area of the Jomon males was larger than that of the modern Japanese. Female Jomon bones were larger than female modern Japanese bones at 50 and $60 \%$ levels. The area of both male and female Jomons was around the same as that of the recent

\section{Cross Section of Femora}

\section{Jomon}

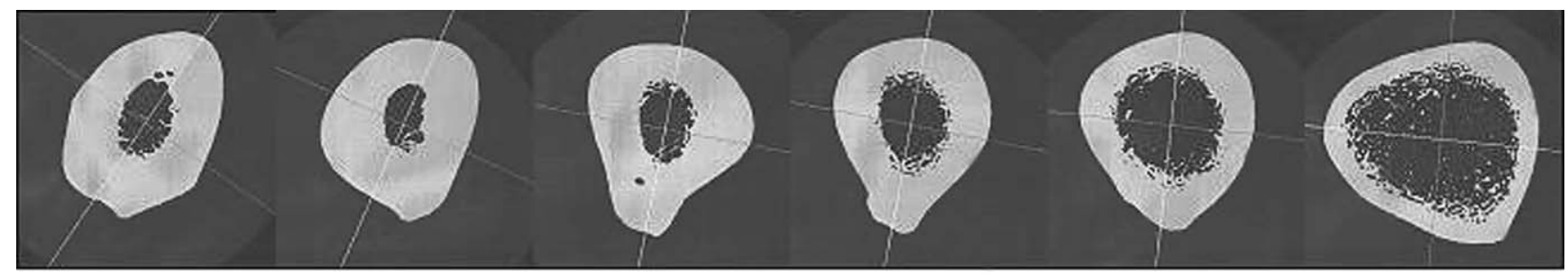

\section{Modern Japanese}

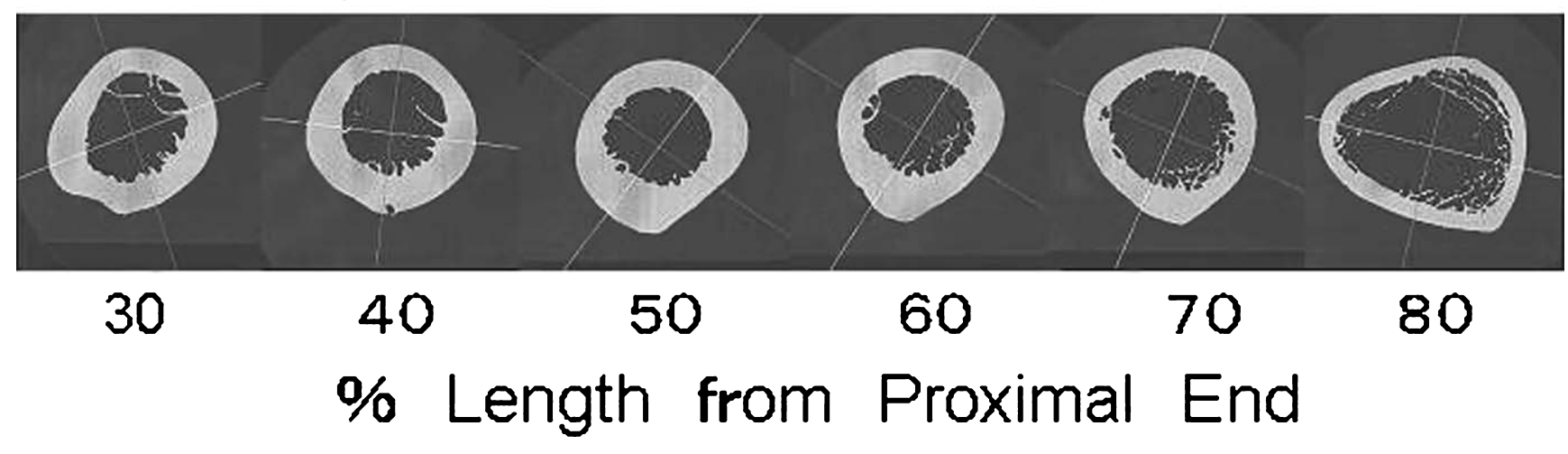

Figure 2. Examples of cross sections. Upper row, a Jomon male (No. KS3); lower row, a modern Japanese male (No. 2097). Thin crossing lines are the principal axes of the cross section. Right femora viewed from the distal end, anterior to the upper side, medial to the right side. 
Table 2. Cross-sectional geometry of the femur

\begin{tabular}{|c|c|c|c|c|c|c|c|c|c|c|c|}
\hline \multirow[b]{2}{*}{ Properties } & \multirow[b]{2}{*}{ Level } & \multicolumn{5}{|c|}{ Male } & \multicolumn{5}{|c|}{ Female } \\
\hline & & Jomon & \multicolumn{2}{|c|}{ Japanese } & \multicolumn{2}{|c|}{ German } & Jomon & \multicolumn{2}{|c|}{ Japanese } & \multicolumn{2}{|c|}{ German } \\
\hline \multicolumn{2}{|l|}{$n$} & 18 & \multicolumn{2}{|c|}{10} & \multicolumn{2}{|c|}{8} & 15 & \multicolumn{2}{|r|}{10} & \multicolumn{2}{|l|}{7} \\
\hline \multirow[t]{6}{*}{ Area $\mathrm{mm}^{2}$} & 30 & $443.5 \pm 34.6$ & $364.6 * *$ & \pm 56.0 & 449.0 & \pm 86.4 & $343.2 \pm 37.5$ & 306.3 & \pm 49.6 & 342.1 & \pm 41.8 \\
\hline & 40 & $454.2 \pm 33.7$ & $369.1 * *$ & \pm 58.3 & 440.1 & \pm 83.3 & $342.5 \pm 33.8$ & $304.5^{*}$ & \pm 45.7 & 335.7 & \pm 45.0 \\
\hline & 50 & $437.2 \pm 33.9$ & $352.5 * *$ & \pm 54.6 & 422.0 & \pm 69.3 & $322.8 \pm 30.6$ & $287.7^{*}$ & \pm 41.1 & 328.9 & \pm 36.0 \\
\hline & 60 & $407.3 \pm 38.2$ & $332.3 * * *$ & \pm 48.4 & 390.3 & \pm 62.3 & $300.4 \pm 29.2$ & $267.2 *$ & \pm 35.9 & 298.4 & \pm 37.0 \\
\hline & 70 & $373.4 \pm 34.1$ & $311.5^{*}$ & \pm 55.9 & 343.1 & \pm 52.5 & $270.7 \pm 29.4$ & 244.7 & \pm 35.0 & 255.9 & \pm 33.3 \\
\hline & 80 & $338.1 \pm 38.0$ & 287.4 & \pm 66.3 & & & $241.6 \pm 28.7$ & 227.6 & \pm 35.0 & & \\
\hline \multirow{6}{*}{$\begin{array}{l}\text { Second moment of area }(I x) \\
10^{4} \mathrm{~mm}^{4}\end{array}$} & 30 & $2.614 \pm 0.518$ & $1.768 * * *$ & ${ }^{*} \pm 0.405$ & $3.118^{* * *}$ & $* \pm 0.775$ & $1.527 \pm 0.245$ & 1.464 & \pm 0.205 & $1.836^{* *}$ & \pm 0.144 \\
\hline & 40 & $2.732 \pm 0.559$ & $1.755^{* * *}$ & \pm 0.355 & 2.639 & \pm 0.558 & $1.463 \pm 0.221$ & 1.345 & \pm 0.163 & 1.647 & \pm 0.230 \\
\hline & 50 & $2.796 \pm 0.568$ & $1.755^{* * *}$ & \pm 0.372 & 2.602 & \pm 0.506 & $1.476 \pm 0.223$ & $1.276^{*}$ & \pm 0.204 & 1.656 & \pm 0.204 \\
\hline & 60 & $2.799 \pm 0.592$ & $1.783 * * *$ & \pm 0.402 & 2.586 & \pm 0.601 & $1.581 \pm 0.270$ & $1.302 *$ & \pm 0.219 & 1.625 & \pm 0.245 \\
\hline & 70 & $2.879 \pm 0.580$ & $1.940 * * *$ & ${ }^{k} \pm 0.502$ & 2.733 & \pm 0.734 & $1.634 \pm 0.229$ & $1.41 *$ & \pm 0.261 & 1.628 & \pm 0.296 \\
\hline & 80 & $3.012 \pm 0.610$ & $2.167 * *$ & \pm 0.676 & & & $1.655 \pm 0.294$ & 1.594 & \pm 0.305 & & \\
\hline Second moment of area (Iy) & 30 & $2.365 \pm 0.417$ & 2.307 & \pm 0.338 & $3.380^{* *}$ & \pm 0.797 & $1.794 \pm 0.326$ & 1.624 & \pm 0.327 & 1.916 & \pm 0.215 \\
\hline & 40 & $2.086 \pm 0.359$ & 2.047 & \pm 0.459 & $2.965^{*}$ & \pm 0.743 & $1.592 \pm 0.295$ & 1.371 & & 1.720 & \pm 0.236 \\
\hline & 50 & $2.028 \pm 0.373$ & $1.790^{*}$ & \pm 0.395 & 2.629 & \pm 0.737 & $1.461 \pm 0.252$ & 1.257 & \pm 0.261 & $1.739 *$ & \pm 0.334 \\
\hline & 60 & $2.026 \pm 0.381$ & 1.729 & \pm 0.331 & $2.621 * *$ & \pm 0.605 & $1.402 \pm 0.192$ & 1.242 & \pm 0.270 & 1.687 & \pm 0.344 \\
\hline & 70 & $2.349 \pm 0.427$ & 2.021 & \pm 0.372 & 2.818 & \pm 0.829 & $1.600 \pm 0.236$ & 1.516 & \pm 0.274 & $1.994 * *$ & \pm 0.376 \\
\hline & 80 & $3.561 \pm 0.723$ & 3.145 & \pm 0.687 & & & $2.339 \pm 0.409$ & 2.459 & \pm 0.377 & & \\
\hline Polar second moment of & 30 & $4.979 \pm 0.870$ & $4.075 * *$ & \pm 0.628 & $6.498^{* *}$ & \pm 1.428 & $3.321 \pm 0.428$ & 3.088 & \pm 0.383 & $3.766^{*}$ & \pm 0.330 \\
\hline & 40 & $4.818 \pm 0.830$ & $3.802 * *$ & \pm 0.714 & 5.604 & \pm 1.140 & $55 \pm 0$. & $2.716^{*}$ & .339 & & \pm 0.365 \\
\hline & 50 & $4.824 \pm 0.854$ & $3.546^{* * *}$ & \pm 0.703 & 5.231 & \pm 1.068 & $2.938 \pm 0.350$ & $2.533^{*}$ & \pm 0.415 & $3.395^{*}$ & \pm 0.443 \\
\hline & 60 & $4.824 \pm 0.906$ & $3.512 * * *$ & ${ }^{k} \pm 0.668$ & 5.207 & \pm 1.096 & $2.983 \pm 0.355$ & $2.544 *$ & \pm 0.450 & 3.312 & \pm 0.495 \\
\hline & 70 & $5.228 \pm 0.950$ & $3.961^{* *}$ & \pm 0.836 & 5.551 & \pm 1.494 & $3.234 \pm 0.394$ & 2.925 & \pm 0.475 & 3.627 & \pm 0.623 \\
\hline & 80 & $6.573 \pm 1.254$ & $5.312 *$ & \pm 1.308 & & & $3.994 \pm 0.657$ & 4.052 & \pm 0.616 & & \\
\hline Maximum & 30 & $2.956 \pm 0.592$ & $2.510^{*}$ & \pm 0.369 & 3.834 & \pm 1.073 & $2.065 \pm 0.296$ & 2.027 & \pm 0.237 & 2.312 & \pm 0.491 \\
\hline & 40 & $2.819 \pm 0.504$ & $2.129 * *$ & \pm 0.423 & 3.201 & \pm 0.631 & $1.729 \pm 0.213$ & 1.608 & \pm 0.186 & 1.836 & \pm 0.180 \\
\hline & 50 & $2.907 \pm 0.537$ & $2.003 * * *$ & \pm 0.405 & 3.018 & \pm 0.561 & $1.653 \pm 0.202$ & $1.401 * *$ & $* \pm 0.231$ & $1.868^{*}$ & \pm 0.232 \\
\hline & 60 & $2.883 \pm 0.570$ & $1.992 * * *$ & \pm 0.356 & 2.898 & \pm 0.586 & $1.688 \pm 0.216$ & $1.400^{* *}$ & $* \pm 0.272$ & 1.808 & \pm 0.302 \\
\hline & 70 & $2.932 \pm 0.541$ & $2.169 * * *$ & \pm 0.441 & 3.006 & \pm 0.818 & $1.754 \pm 0.203$ & 1.610 & \pm 0.276 & 2.018 & \pm 0.372 \\
\hline & 80 & $3.619 \pm 0.709$ & 3.195 & \pm 0.683 & & & $2.376 \pm 0.427$ & 2.498 & \pm 0.375 & & \\
\hline Minimum & 30 & $2.023 \pm 0.343$ & $1.565^{*}$ & \pm 0.403 & $2.663 * * *$ & $* \pm 0.458$ & $1.256 \pm 0.223$ & $1.061 *$ & \pm 0.158 & $1.583 * *$ & \pm 0.10 \\
\hline & 40 & $1.999 \pm 0.377$ & $1.673 *$ & \pm 0.338 & $2.403 *$ & \pm 0.554 & $1.326 \pm 0.217$ & $1.108^{*}$ & \pm 0.201 & 1.531 & \\
\hline & 50 & $1.917 \pm 0.402$ & $1.543^{*}$ & \pm 0.331 & 2.214 & \pm 0.515 & $1.285 \pm 0.197$ & 1.132 & \pm 0.215 & $1.528 *$ & \pm 0.244 \\
\hline & 60 & $1.941 \pm 0.407$ & $1.519^{*}$ & \pm 0.363 & 2.309 & \pm 0.522 & $1.295 \pm 0.185$ & 1.143 & \pm 0.196 & $1.505^{*}$ & \pm 0.229 \\
\hline & 70 & $2.296 \pm 0.447$ & $1.792 * *$ & \pm 0.418 & 2.545 & \pm 0.702 & $1.480 \pm 0.219$ & 1.315 & \pm 0.224 & 1.609 & \pm 0.293 \\
\hline & 80 & $2.954 \pm 0.612$ & $2.116^{* *}$ & \pm 0.654 & & & $1.618 \pm 0.282$ & 1.555 & \pm 0.309 & & \\
\hline & 30 & $1.051 \pm 0.078$ & $0.875^{* * *}$ & \pm 0.088 & $0.963 *$ & \pm 0.085 & $0.929 \pm 0.104$ & 0.960 & \pm 0.117 & 0.981 & \pm 0.0 \\
\hline & 40 & $1.144 \pm 0.100$ & $0.932 * * *$ & $* 0.099$ & $0.956 * *$ & \pm 0.111 & $0.967 \pm 0.113$ & 1.001 & \pm 0.111 & 0.982 & \pm 0.08 \\
\hline & 50 & $1.174 \pm 0.107$ & $0.994 * * *$ & \pm 0.089 & $1.017^{*}$ & \pm 0.142 & $1.013 \pm 0.114$ & 1.015 & \pm 0.096 & 0.985 & \pm 0.10 \\
\hline & 60 & $1.174 \pm 0.102$ & $1.016^{* * *}$ & ${ }^{*} \pm 0.093$ & $1.001 * *$ & \pm 0.104 & $1.064 \pm 0.113$ & 1.030 & \pm 0.081 & 0.988 & \pm 0.09 \\
\hline & 70 & $1.106 \pm 0.080$ & $0.976 * * *$ & \pm 0.073 & $0.993 * *$ & \pm 0.077 & $1.014 \pm 0.081$ & 0.967 & \pm 0.080 & $0.906 * *$ & \pm 0.06 \\
\hline & 80 & $0.921 \pm 0.062$ & $0.825^{* *}$ & \pm 0.067 & & & $0.843 \pm 0.053$ & 0.805 & \pm 0.058 & & \\
\hline Cross-s & 30 & $1.209 \pm 0.094$ & 1.284 & \pm 0.155 & 1.190 & \pm 0.124 & $1.291 \pm 0.123$ & $1.386^{*}$ & \pm 0.052 & 1.202 & \pm 0.094 \\
\hline$(\mathrm{kmax} / \mathrm{kmin})$ & 40 & $1.190 \pm 0.073$ & 1.131 & \pm 0.083 & 1.159 & \pm 0.063 & $1.148 \pm 0.088$ & 1.213 & \pm 0.093 & 1.098 & \\
\hline & 50 & $1.236 \pm 0.109$ & $1.141^{*}$ & \pm 0.07 & 1.175 & \pm 0.045 & $1.138 \pm 0.075$ & 1.117 & \pm 0.076 & 1.109 & \pm 0.05 \\
\hline & 60 & $1.221 \pm 0.100$ & 1.152 & \pm 0.089 & $1.124 * *$ & \pm 0.038 & $1.145 \pm 0.077$ & 1.106 & \pm 0.061 & 1.096 & \pm 0.06 \\
\hline & 70 & $1.132 \pm 0.065$ & 1.103 & \pm 0.058 & 1.088 & \pm 0.051 & $1.092 \pm 0.059$ & 1.108 & \pm 0.063 & 1.122 & \pm 0.07 \\
\hline & 80 & $1.110 \pm 0.073$ & $1.241 * * *$ & \pm 0.082 & & & $1.214 \pm 0.086$ & 1.274 & \pm 0.090 & & \\
\hline Relative area $L^{2} / 10^{4}$ & 30 & $25.12 \pm 1.69$ & 23.45 & \pm 4.36 & 21.64 & \pm 4.74 & $22.44 \pm 3.03$ & 20.41 & \pm 3.24 & $18.05^{* *}$ & \pm 2.88 \\
\hline & 40 & $25.71 \pm 1.43$ & 23.74 & \pm 4.46 & $21.20^{*}$ & \pm 4.52 & $22.42 \pm 3.07$ & 20.32 & \pm 3.11 & $17.67^{* *}$ & \pm 2.70 \\
\hline & 50 & $24.75 \pm 1.57$ & 22.70 & \pm 4.41 & $20.30 *$ & \pm 3.80 & $21.14 \pm 2.88$ & 19.19 & \pm 2.78 & $17.31^{* *}$ & \pm 2.24 \\
\hline & 60 & $23.05 \pm 1.80$ & 21.40 & \pm 4.07 & $18.80^{*}$ & \pm 3.61 & $19.64 \pm 2.48$ & 17.85 & \pm 2.63 & $15.68^{* *}$ & \pm 2.12 \\
\hline & 70 & $21.16 \pm 1.98$ & 20.08 & \pm 4.45 & $16.48^{* *}$ & \pm 2.71 & $17.69 \pm 2.38$ & 16.37 & \pm 2.63 & $13.44 * * *$ & \pm 1.76 \\
\hline & 80 & $19.18 \pm 2.40$ & 18.51 & \pm 4.94 & & & $15.81 \pm 2.39$ & 15.24 & \pm 2.77 & & \\
\hline
\end{tabular}

Values are mean \pm standard deviation, $L$ refers to maximum length.

Significance level from Jomon bones of the same sex: ${ }^{*}, P<0.05 ; * *, P<0.01 ; * * *, P<0.001$. 
Table 2. (continued)

\begin{tabular}{|c|c|c|c|c|c|c|c|c|}
\hline \multirow[b]{2}{*}{ Properties } & \multirow[b]{2}{*}{ Level } & \multicolumn{4}{|c|}{ Male } & \multicolumn{3}{|c|}{ Female } \\
\hline & & Jomon & Japanese & \multicolumn{2}{|c|}{ German } & Jomon & Japanese & German \\
\hline$n$ & & 18 & 10 & \multicolumn{2}{|l|}{8} & 15 & 10 & 7 \\
\hline \multirow{6}{*}{$\begin{array}{l}\text { Relative second moment of } \\
\text { area }(I x) L^{4} / 10^{8}\end{array}$} & 30 & $83.25 \pm 12.97$ & $72.19 \pm 15.76$ & 72.62 & \pm 22.13 & $64.96 \pm 11.30$ & $66.37 \pm 16.40$ & $51.61 * \pm 11.48$ \\
\hline & 40 & $86.96 \pm 14.40$ & $71.65^{*} \pm 14.13$ & $61.17 * *$ & \pm 15.23 & $62.44 \pm 11.44$ & $61.05 \pm 14.81$ & $45.73 * * \pm 7.95$ \\
\hline & 50 & $89.10 \pm 16.00$ & $71.94 * \pm 16.09$ & $60.14 * * *$ & ${ }^{*} \pm 13.55$ & $63.00 \pm 11.32$ & $57.67 \pm 14.26$ & $46.01 * * \pm 8.08$ \\
\hline & 60 & $89.17 \pm 17.01$ & $72.87 * \pm 16.22$ & $59.29 * * *$ & ${ }^{*} \pm 13.65$ & $67.25 \pm 12.04$ & $58.54 \pm 13.47$ & $45.27 * * * \pm 9.59$ \\
\hline & 70 & $91.83 \pm 16.12$ & $79.52 \pm 20.25$ & $62.57 * * *$ & ${ }^{*} \pm 15.26$ & $69.68 \pm 11.74$ & $62.82 \pm 11.79$ & $45.47 * * * \pm 11.52$ \\
\hline & 80 & $96.00 \pm 15.79$ & $88.58 \pm 26.28$ & & & $70.56 \pm 13.60$ & $70.93 \pm 12.96$ & \\
\hline \multirow{6}{*}{$\begin{array}{l}\text { Relative second moment of } \\
\text { area }(I y) L^{4} / 10^{8}\end{array}$} & 30 & $75.61 \pm 10.87$ & $96.03 * \pm 24.59$ & 77.62 & \pm 17.38 & $76.61 \pm 15.99$ & $72.45 \pm 15.50$ & $54.22 * * \pm 14.97$ \\
\hline & 40 & $66.68 \pm 8.81$ & $85.04 * \pm 24.12$ & 68.34 & \pm 17.95 & $67.98 \pm 14.51$ & $61.38 \pm 14.15$ & $48.65 * * \pm 13.68$ \\
\hline & 50 & $64.81 \pm 9.23$ & $74.33 \pm 20.55$ & 60.42 & \pm 17.11 & $62.46 \pm 13.04$ & $56.52 \pm 14.65$ & $49.55 \pm 16.86$ \\
\hline & 60 & $64.71 \pm 9.34$ & $71.57 \pm 17.85$ & 60.90 & \pm 16.62 & $60.26 \pm 12.83$ & $56.15 \pm 16.09$ & \pm 17.35 \\
\hline & 70 & $75.06 \pm 10.68$ & $83.07 \pm 17.33$ & 64.65 & \pm 18.40 & $68.93 \pm 16.09$ & $68.43 \pm 17.64$ & \pm 19.75 \\
\hline & 80 & $113.72 \pm 18.91$ & $129.80 \pm 32.22$ & & & $100.54 \pm 24.22$ & $110.95 \pm 26.07$ & \\
\hline \multirow{6}{*}{$\begin{array}{l}\text { Relative polar second } \\
\text { moment of area (Ip) } L^{4} / 10^{8}\end{array}$} & 30 & $158.86 \pm 20.27$ & \pm 36.19 & 150.23 & \pm 37.20 & $141.58 \pm 21.84$ & $138.82 \pm 26.44$ & $106.24 * * \pm 26.21$ \\
\hline & 40 & $153.63 \pm 18.96$ & $156.69 \pm 35.13$ & $129.51 *$ & \pm 29.88 & $130.42 \pm 20.74$ & $122.43 \pm 25.20$ & $94.38 * * \pm 20.49$ \\
\hline & 50 & $153.91 \pm 21.45$ & $146.27 \pm 34.53$ & $120.56 * *$ & \pm 26.97 & $125.46 \pm 19.97$ & $114.19 \pm 26.46$ & $95.56^{* *} \pm 24.28$ \\
\hline & 60 & $153.87 \pm 23.39$ & \pm 31.44 & $120.19 * *$ & \pm 27.95 & $127.51 \pm 20.97$ & $114.69 \pm 27.89$ & $93.30 * * \pm 25.69$ \\
\hline & 70 & $166.89 \pm 24.36$ & $162.60 \pm 35.69$ & $127.22 * *$ & \pm 31.99 & $138.61 \pm 25.55$ & $131.25 \pm 27.59$ & $102.42 * * \pm 30.59$ \\
\hline & 80 & $209.71 \pm 31.54$ & $218.38 \pm 55.03$ & & & $171.11 \pm 36.14$ & $181.88 \pm 37.17$ & \\
\hline
\end{tabular}

Values are mean \pm standard deviation, $L$ refers to maximum length.

Significance level from Jomon bones of the same sex: ${ }^{*}, P<0.05 ; * *, P<0.01 ; * * *, P<0.001$

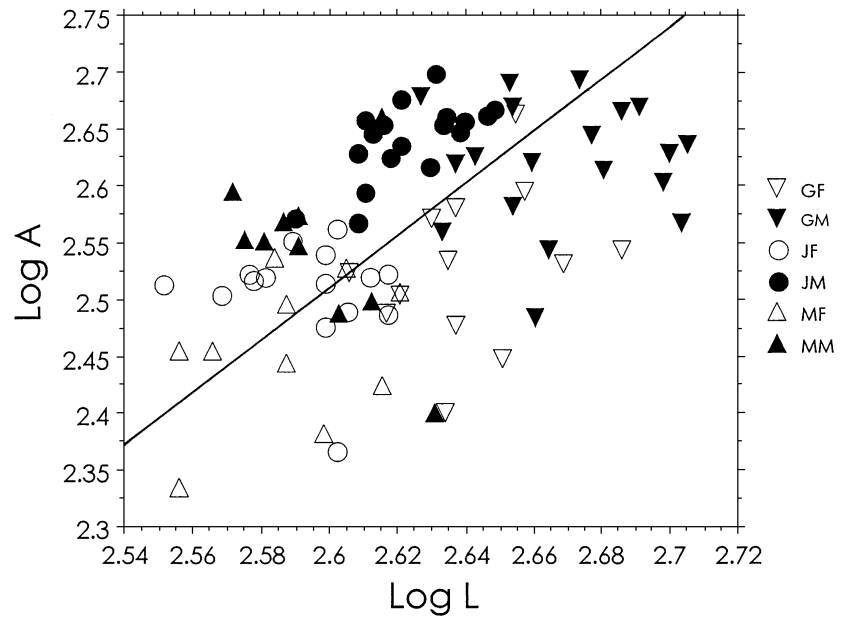

Figure 3. Scatter diagram between maximum length $(L \mathrm{~mm})$ and cross-sectional area $\left(A \mathrm{~mm}^{2}\right)$ at mid-length, transformed in common logarithm. The line is the reduced major axis, $y=2.297 x-3.465$ $(P<0.0001)$. The slope of the reduced major axis is not significantly different from 2. G, Germans; J, Jomon people; M, modern Japanese; $\mathrm{F}$, females; and $\mathrm{M}$, males.

Germans. Correlation between length and area at the 50\% level, after logarithmic transformation, was significant $(r=0.460)$ (Figure 3). The German sample in Figure 3 consists of all 32 mid-length cross sections. The slope of the reduced major axis analysis was 2.30 , indicating slight positive allometry, but not significantly different from 2.0 $(P>0.1)$, when considering that the area is the second power of length.

The polar second moment of area (Ip) in the Jomon males was larger than in modern Japanese males at all levels. It was larger in the Jomon females than in modern Japanese females at the 40, 50, and 60\% levels. The German bones showed a larger polar second moment than the Jomon bones at a few levels. A significant correlation $(r=0.695)$ was observed between the length of bone and the polar second moment of area at mid-length after logarithmic transformation (Figure 4). The slope of the reduced major axis was 3.75 , showing slight negative allometry, but not significantly different from $4.0(P>0.3)$, when considering that $I p$ is the fourth power of length. On the other hand, the slope was significantly different from $3.0(P<0.01)$.

With the second moment of area around the frontal plane, in other words, the $x$-axis on the cross section, Jomon males had significantly larger moments at all levels of cross section than modern Japanese males. Jomon females were also larger than modern Japanese females at cross sections of 50, 60 , and $70 \%$. The Jomon bones were around the same size as the German bones except at the 30\% level, where both male and female Jomon femora were smaller than those of the Germans. On the other hand, the Jomon bones were not significantly larger than the modern Japanese bones in the second moment of area around the anteroposterior plane (Iy) except at the $50 \%$ cross-section in males. The Jomon bones were smaller than the German bones at many levels. Significant correlations were observed at the $50 \%$ level between the length and both second moments of area ( $I x$ and $I y$, $r=0.643$ and 0.668 , respectively). Slopes of the reduced major axis were 4.17 and 3.79 , respectively, and not significantly different from $4.0(P>0.6$ and $P>0.5$, respectively) and significantly different from $3.0(P<0.01$ and $P<0.001$, respectively).

The cross-sectional index along the $x-y$ axes $(k x / k y)$ was 


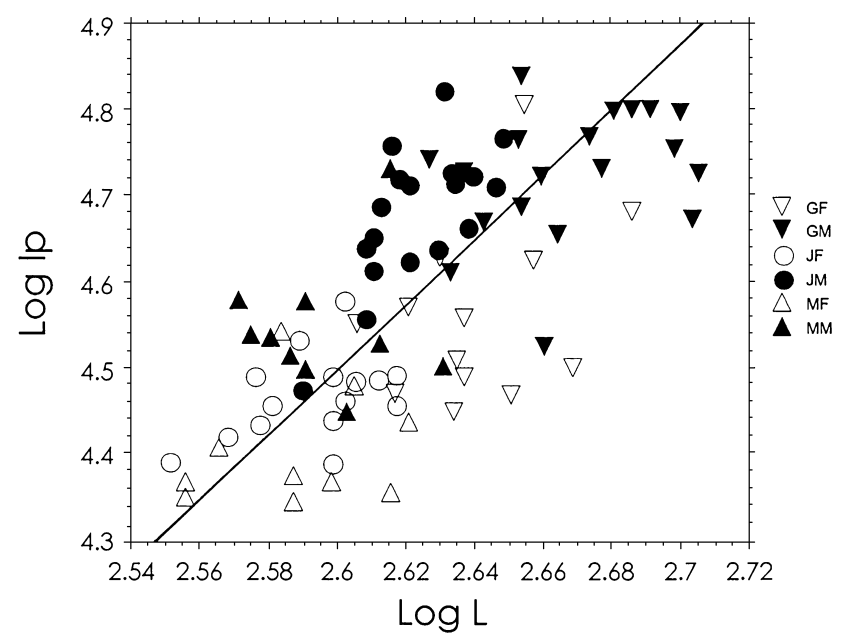

Figure 4. Scatter diagram between the maximum length $(L \mathrm{~mm})$ and the polar second moment of area $\left(I p \mathrm{~mm}^{4}\right)$ at mid-length, transformed in common logarithm. The line is the reduced major axis, $y=3.747 x-5.247(P<0.0001)$. The slope is not significantly different from 4. See Figure 3 for abbreviations.

significantly larger in the male Jomon bones than in other groups at all levels (Figure 5). The index was greater than 1.0 except at the $80 \%$ level. The average indices of the female Jomon bones were greater than 1.0 from the 50 to $70 \%$ levels and were significantly larger than those of the female German bones at the $70 \%$ level.

The maximum (Imax) and the minimum (Imin) second moments of area were both larger in the Jomon males than in the modern Japanese males. The Jomon females were also larger in the Imax, at the middle part of the shaft, and in the Imin, at the proximal part of the shaft. Because of the large Imin, the cross-sectional index along the principal axes $(\mathrm{kmax} / \mathrm{kmin})$ was not especially large in the Jomon bone except at the middle part in males, where the Jomon bone was larger than both the modern Japanese and German bones. The principal axis of most male Jomon bones on this part ran around $10^{\circ}$ clockwise from the anterior side, that is, nearly in the anteroposterior direction (see Figure 2). On the other hand, the male modern Japanese femur had a larger value of the index than the male Jomon femur at the lower end level of the shaft. The maximum principal axis of both groups at the $80 \%$ level ran nearly anteroposteriorly, about $100^{\circ}$ anticlockwise from the lateral side on average. The average angle at this level was the same in the case of females in both the Jomon and modern Japanese.

The relative area of the Jomon bones was significantly larger than that of German bones except at the $30 \%$ level in males. That of the Jomon bones was larger than in the modern Japanese bones, but the difference was not significant. The relative polar second moment was significantly larger in the Jomon bones than in the German bones except at the $30 \%$ level in males. The relative $I x$ was significantly larger in the Jomon bones than in the German bones except at the $30 \%$ level in males. That of the Jomon males was significantly larger than in the modern Japanese males at the middle part. The relative $I y$ of Jomon females was significantly larger than that of German females at the 30 and $40 \%$ levels. On the other hand, that of the Jomon males was significantly smaller than in the modern Japanese males at the 30 and $40 \%$ levels.

\section{Discussion}

The outer diameter of the femoral shaft becomes larger in elderly individuals (Martin and Atkinson, 1977; Ruff and Hayes, 1982), so the second moments of area and the polar second moment of area become larger in the elderly (Ruff,

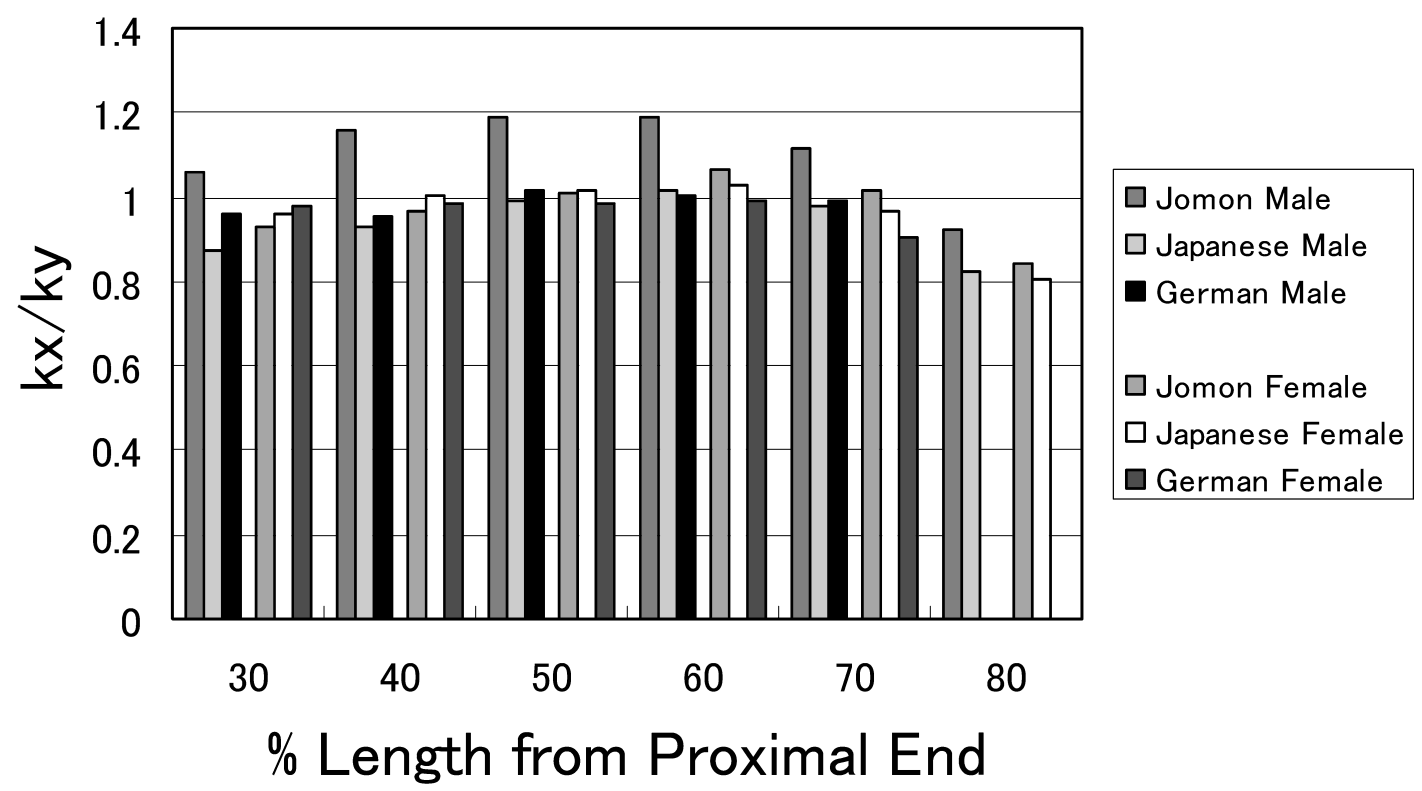

Figure 5. Cross-sectional index $(k x / k y)$ along the bone length. Jomon males show significantly larger values than the other groups at all levels. Cross-sectional indices from 50 to $70 \%$ levels of the Jomon femoral shafts are larger than 1.0 in both sexes. 
1992; Kimura, 1994). Greater geometrical robustness will compensate for the weakening of bone substance along with aging (Ruff, 1992; Pearson and Lieberman, 2004). Since the expansion of the shaft will be a physiological adaptation during the life history of an individual, it is not easy to compare directly the ancient bones with recent ones only from the perspective of chronological age. But we should consider the influence of age.

The ages of the present Jomon samples were not estimated because there were not many individuals with sufficiently preserved innominate bones which are the most reliable part of the bone for estimating adult age. According to Kobayashi (1967), the average ages at death of those who died at an age greater than 15 were 32.4 and 32.3 for Middle Jomon males and females, respectively, and 30.9 and 31.4 for Late and Latest Jomon males and females, respectively. There were very few individuals over 60 years, less than $1 \%$ of the sample. Age at death of the Kobayashi (1967) report was estimated from certain morphological patterns, which differ with chronological age, based on recent bones. Probably there are relationships between physiological aging in the expansion of femora and in the morphological patterns used by Kobayashi (1967). Individuals under 20 years, whose bones have not matured, made up about $10 \%$ of his sample. When excluding these individuals, the average age at death of both sexes must be raised by more than one year. Modern Japanese samples in the present study were purposely selected so as to be less than 60 years of age in order to make the influence of the age small when comparing with the Jomon bones. If the average ages of the present Jomon sample were the same as those of the above report, they were still several years younger than those of the modern Japanese, 37 for males and 39 for females, but the difference is not very large. Both groups included very few elderly people. The influence of age will be minimal in the comparison between the two groups. On the other hand, most of the German sample, over $80 \%$, consisted of those aged more than 60 years. The large values of the geometrical properties in the German bones must be partly influenced by the effect of age. The severe porosity observed at the $80 \%$ level of the German bones compared to other groups could be caused by their old age.

The area of bone cross section is an indicator of the volume of bone substance. The large area of the Jomon bone, in both males and females, shows a large volume. Bone area also indicates resistance against axial force. In long bones, however, axial force is usually not important from the adaptive viewpoint. Bending moment is the most important (Kimura, 1974; Rubin and Lanyon, 1982).

The second moment of area usually indicates resistance against bending moments. The polar second moment of area (Ip) is the sum of two second moments of area crossing at a right angle, so that it indicates overall resistance against bending moments. It also roughly indicates resistance against torque. In males, I $p$ was larger in Jomon bones than in modern Japanese bones along the whole bone shaft. In females, Jomon bones had larger I $p$ values than in modern Japanese at the middle part of the bone. Jomon femora were generally more robust than modern Japanese ones against moments applied from the outside. The large second moment of area around the $x$-axis ( $I x$ ) of Jomon males along the entire femur shaft indicates greater robustness against bending moments in the anteroposterior direction. The principal axis also pointed close to the anteroposterior direction at the middle part of the shaft. Portions of the Jomon female femoral shaft also showed the same tendency. On the other hand, robustness against bending moments in the transverse direction (Iy) was not particularly large in the Jomon femur along the whole shaft. It was relatively small in the upper part of the male shaft.

The Jomon bones had directivity against the bending moment especially in the anteroposterior direction. This was clearly shown by the cross-sectional index. The ratio of radii of gyration along the $x$ - and $y$-axes $(k x / k y)$ was larger in the Jomon males than in the other groups along the whole shaft. The ratio in females showed the same tendency but less clearly. Though there can be many possible reasons other than mechanical stimulation for a change in bone shape, the anteroposterior direction of the femur is the direction of femoral movement in daily locomotion and also the direction in which the muscles are active. The anteroposterior direction will be a functionally adaptive characteristic for the daily activity of hunter-gatherers (Kimura and Takahashi, 1982; Ruff, 1987). The pilaster of the shaft, which is frequently seen in their femora, works to enlarge the directional tendency. These characteristics of the Jomon femur have already been shown and discussed at the $50 \%$ level of the bone (Kimura and Takahashi, 1982). The present analysis showed that the anteroposterior directivity was along the whole shaft in Jomon males and some part of the shaft in females.

The general robustness and mechanical rigidity in the anteroposterior direction at mid-shaft, particularly in males, were reported also on many anatomically modern huntergatherers (Kimura and Takahashi, 1992; Ruff et al., 1993; Trinkaus, 1997; Holt, 2003). The difference between the preagricultural and agricultural femora from the Georgia coast has been discussed at the mid-shaft and the subtrochanteric section (Ruff et al., 1984). The reduction of the geometrical properties and the more circular shape of the agricultural group were reported. Jomon femora were not particularly flat at the proximal end of the shaft, unlike those of the Georgia coast. Holt (2003) reported the lack of a clear trend in sexual dimorphism in the Upper Palaeolithic and Mesolithic European skeletons and discussed it in terms of mobility and labor. Though the tendency was the same, a sexual difference in Jomon femora was noticeable in their robustness. Jomon people were basically sedentary huntergatherers. There may have been a sexual division of labor among them.

Size was normalized here by bone length, as described by Ruff (1984). Usually the size of animals is represented by body mass. It is difficult to estimate the body mass of ancient people including the Jomon individuals of the present study. A complicated estimation of body mass will introduce uncontrollable errors. Correlation between dead body mass and $A$ or $I p$ was not significant in Japanese tibiae (Kimura, 1971). In this case, none of the sample died accidentally but usually after bed rest. Dead body mass is not a good indicator of size in humans. Muscle activity should be considered 
when the bending moment of bone is standardized (Kimura, 2003). But the influence of muscle on bone normalization is difficult to estimate and this remains to be considered in future analysis.

In the present data, correlations between the geometrical properties and the length of bone after logarithmic transformation proved that relative properties versus body size can be evaluated to a certain extent by standardizing on simple analogues of bone length. Absolute values of the German bones were larger than those of other groups. The differences can be influenced by old-age expansion and also by genetic differences. The relative dimensionless values of Germans were generally smaller than other groups, especially in relative area, relative $I p$, and relative $I x$. The German bones did not have great robustness when standardized by length. This is also shown in Figure 3 and Figure 4, where the German bones scatter lower than the Jomon bones, when comparisons are made in the same length interval.

Recently, Lieberman and others (2004) concluded that cross-sectional properties do not necessarily provide reliable data on the orientation of loads to which bones are subjected. By means of strain gauges, they measured in vivo strains around the tibia and metatarsal mid-shafts of sheep during slow treadmill running within about 24 hours after surgery. In these animals, orientation of the principal centroidal axes around which the maximum second moments of area are calculated were not in the same planes in which the subjects experienced bending. Both bones were loaded with a large anteroposterior bending during the stance phase, concave posteriorly in the tibia and anteriorly in the metatarsus. But the maximum second moment of area of tibia was directed mediolaterally and that of metatarsus was directed at $45^{\circ}$, which is caused by the nearly circular tube of the cross section. The results differed from those reported on the metapodial shafts of horses during in vivo locomotion at different speeds several days after surgery (Biewener et al., 1983, 1988; Davis et al., 1993). The bending load was very small on the horse metapodials and the compressive strain was usually observed both at the cranial and caudal surfaces of the bone during the whole stance phase.

The upper and lower ends of the tibia and metapodials spread mediolaterally in order to meet the mechanical requirement of hinge joints, which rotate around the mediolateral axis. The shaft of the tibia curves concave posteriorly particularly at the upper half. Even when only axial compression is applied through the upper and lower articular centers of tibia, the upper part of tibia undergoes nearly anteroposterior bending because of the eccentric loading, both in the human and the horse (Kimura, 1974). When the muscles on the anterior surface are active, then the bending becomes large, but when the muscles on the posterior surface are active, the bending is compensated for (Kimura, 1966, 1974). A roughly anteroposterior bending during locomotion is observed also in in vivo measurements of the tibiae of goats (Biewener and Taylor, 1986), dogs (Rubin and Lanyon, 1982), and horses (Biewener et al., 1988). The lower end of the human tibia makes a hinge joint and spreads mediolaterally, and suffers mainly compression and hardly any bending (Kimura, 1974). In sheep tibia, the shape of the mid-shaft can be influenced mainly by the mechanical pur- pose of the hinge-shaped lower articulation. Metapodials are usually straight. There are no muscle attachments on their shaft. Under axial compression, a uniform compressive strain is observed around the horse metatarsus (Kimura, 1974), as in the case of horse metapodials during locomotion (Biewener et al., 1983, 1988; Davis et al., 1993). In the case of sheep metatarsus, eccentric compression was probably applied from the upper and lower joints. There may be some mechanical reasons to be analyzed. Forces applied on the bone should be always considered together with muscle activity.

"Mechanical stimulation is not the only factor responsible for the orientation and replacement of osteons" as Evans (1957) declared. But the relationship between the shape of long bones including geometrical properties (Kimura, 1966, 1974; Carter et al., 1981; Biewener et al., 1983; Szivek et al., 1992) and mechanical robustness has been experimentally proved by his work and also by subsequent studies. Mechanical differences in the long bone shaft among modern human groups can be analyzed to some extent from the geometrical properties.

\section{Acknowledgments}

For collecting Jomon and modern Japanese materials and figuring the cross section, I am indebted to Dr. G. Suwa, Ms. M. Chubachi, and Ms. M. Takahashi. For German bones, I thank the late Prof. E. Amtmann and Ms. K. Westerman. For editorial help, I wish to acknowledge the advice of Dr. J. Power. A part of the study was reported in the Joint Congress of the 55th Meeting of the Anthropological Society of Nippon and the 17th Annual Congress of Primate Society of Japan, Kyoto, 2001 and the 16th International Congress of the International Federation of Association of Anatomists, Kyoto, 2004.

\section{References}

Bass S.L., Saxon, L., Daly R.M., Turner, C.H., Robling, A.G., Seeman, E., and Stuckey, S. (2002) The effect of mechanical loading on the size and shape of bone in pre-, peri-, and postpubertal girls: a study in tennis players. Journal of Bone and Mineral Research, 17: 2274-2280.

Biewener A.A. and Taylor C.R. (1986) Bone strain: a determinant of gait and speed? Journal of Experimental Biology, 123: $383-400$.

Biewener A.A., Thomason J., Goodship A., and Lanyon L.E. (1983) Bone stress in the horse forelimb during locomotion at different gaits: a comparison of two experimental methods. Journal of Biomechanics, 16: 565-576.

Biewener, A.A., Thomason, J., and Lanyon, L.E. (1988) Mechanics of locomotion and jumping in the horse (Equus): in vivo stress in the tibia and metatarsus. Journal of Zoology (London), 214: 547-565.

Brock S.L. and Ruff C.B. (1988) Diachronic patterns of change in structural properties of the femur in the prehistoric American Southwest. American Journal of Physical Anthropology, 75: $113-127$.

Carter DR, Vasu R., Spengler D.M., and Dueland R.T. (1981) Stress fields in the unplanted and planted canine femur calculated from in vivo strain measurements. Journal of Biomechanics, 14: 63-70.

Davis H.M.S., McCarthy R.N., and Jeffcott L.B. (1993) Surface 
strain on the dorsal metacarpus of thoroughbreds at different speeds and gaits. Acta Anatomica, 146: 148-153.

Endo B. and Kimura T. (1970) Postcranial skeleton of the Amud man. In: Suzuki H. and Takai F. (eds.), The Amud Man and His Cave Site. The University of Tokyo, Tokyo, pp. 231-406.

Evans F.G. (1957) Stress and Strain in Bones. Charles C. Thomas, Springfield, Illinois.

Hofman M.A. (1988) Allometric scaling in palaeontology: a critical survey. Human Evolution, 3: 177-188.

Holt B.M. (2003) Mobility in Upper Paleolithic and Mesolithic Europe: evidence from the lower limb. American Journal of Physical Anthropology, 122: 200-215.

Kimura T. (1966) An experimental study of the form of the human tibia from the biomechanical point of view. The Journal of the Anthropological Society of Nippon, 74: 219-227.

Kimura T. (1971) Cross section of human lower leg bones viewed from strength of materials. Journal of the Anthropological Society of Nippon, 79: 323-336.

Kimura T. (1974) Mechanical characteristics of human lower leg bones. Journal of the Faculty of Science, The University of Tokyo, Section 5, Anthropology, Volume 4, Part 4, pp. 319393

Kimura T. (1994) Age changes of postcranial skeletons in adult Japanese macaques. Anthropological Science, 102 (supplement): $27-41$.

Kimura T. (2003) Differentiation between fore- and hindlimb bones and locomotor behaviour in primates. Folia Primatologica 74: 17-32.

Kimura T. and Amtmann E. (1984) Distribution of mechanical robustness in the human femoral shaft. Journal of Biomechanics, 17: 41-46.

Kimura T. and Takahashi H. (1982) Mechanical properties of cross section of lower limb long bones in Jomon man. Journal of the Anthropological Society of Nippon, 90 (supplement): $105-118$.

Kimura T. and Takahashi H. (1984) On the cross section of lower limb long bones in Minatogawa man from Okinawa. Journal of the Anthropological Society of Nippon, 92: 69-78.

Kimura T. and Takahashi H. (1992) Cross sectional geometry of the Minatogawa limb bones. In: Akazawa T., Aoki K., and Kimura T. (eds.), The Evolution and Dispersal of Modern Humans in Asia. Hokusen-sha, Tokyo, pp. 305-320.

Kobayashi K. (1967) Trend in the length of life based on human skeletons from prehistoric to modern times in Japan. Journal of the Faculty of Science, The University of Tokyo, Section 5, Anthropology, Volume 3, Part 2: 107-162.

Kondo O. (1994) The skull of Ubayama shell-mounds. II. an analysis of intra- and inter-regional variation of the Jomon population. Anthropological Science, 102: 59-74.

Lieberman D.E., Polk J.D., and Demes B. (2004) Predicting long bone loading from cross-sectional geometry. American Journal of Physical Anthropology, 123: 156-171.

Lovejoy C.O. and Trinkaus E. (1980) Strength and robusticity of the Neandertal tibia. American Journal of Physical Anthropology, 53: 465-470.

Martin R. (1928) Lehrbuch der Anthropologie. 2 Band, Kraniologie, Osteologie. Gustav Fischer, Jena.

Martin R.B. and Atkinson P.J. (1977) Age and sex-related changes in the structure and strength of the human femoral shaft. Journal of Biomechanics, 10: 223-231.

Pearson O.M. and Lieberman D.E. (2004) The aging of Wolff's "law": ontogeny and responses to mechanical loading in cortical bone. Yearbook of Physical Anthropology, 47: 63-99.

Rubin C.T. and Lanyon L.E. (1982) Limb mechanics as a function of speed and gait: a study of functional strains in the radius and tibia of horse and dog. Journal of Experimental Biology, 101: $187-211$.

Ruff C.B. (1984) Allometry between length and cross-sectional dimensions of the femur and tibia in Homo sapiens sapiens.
American Journal of Physical Anthropology, 65: 347-358.

Ruff C.B. (1987) Sexual dimorphism in human lower limb bone structure: relationship to subsistence strategy and sexual division of labor. Journal of Human Evolution, 16: 391-416.

Ruff C.B. (1992) Biomechanical analyses of archaeological human skeletal samples. In: Saunders S.R. and Katzenberg M.A. (eds.), Skeletal Biology of Past Peoples: Research Methods. Wiley-Liss, New York, pp. 190-203.

Ruff C.B. (1995) Biomechanics of the hip and birth in early Homo. American Journal of Physical Anthropology, 98: 527-574.

Ruff C.B. (1999) Skeletal structure and behavioral patterns of prehistoric Great Basin populations. In: Hemphill B.E. and Larsen C.S. (eds.), Prehistoric Lifeways in the Great Basin Wetlands: Bioarchaeological Reconstruction and Interpretation. University of Utah Press, Salt Lake City, pp. 290-320.

Ruff C.B. and Hayes W.C. (1982) Subperiosteal expansion and cortical remodeling of the human femur and tibia with aging. Science, 317: 945-947.

Ruff C.B. and Hayes W.C. (1983a) Cross-sectional geometry of Pecos Pueblo femora and tibiae - a biomechanical investigation, I: method and general patterns of variation. American Journal of Physical Anthropology, 60: 359-381.

Ruff C.B. and Hayes W.C. (1983b) Cross-sectional geometry of Pecos Pueblo femora and tibiae - a biomechanical investigation, II: sex, age, and side differences. American Journal of Physical Anthropology, 60: 383-400.

Ruff C.B., Larsen C.S., and Hayes W.C. (1984) Structural changes in the femur with the transition to agriculture on the Georgia coast. American Journal of Physical Anthropology, 64: 125136.

Ruff C.B., Trinkaus E., Walker A., and Larsen C.S. (1993) Postcranial robusticity in Homo, 1: temporal trends and mechanical interpretation. American Journal of Physical Anthropology, 91: 21-53.

Stock J. and Pfeiffer S. (2001) Linking structural variability in long bone diaphysis to habitual behaviors: foraging from the southern African Late Stone Age and the Andaman Islands. American Journal of physical Anthropology, 115: 337-348.

Szivek J.A., Johnson E.M., and Magee F.P. (1992) In vivo strain analysis of the greyhound femoral diaphysis. Journal of Investigative Surgery, 5: 91-108.

Trinkaus E. (1997) Appendicular robusticity and the paleobiology of modern human emergence. Proceedings of National Academy of Sciences of the United States of America, 94: 1336713373.

Trinkaus E. (1999a) Diaphyseal cross-sectional geometry of Near Eastern Middle Palaeolithic humans: the humerus. Journal of Archaeological Science, 26: 173-184.

Trinkaus E. (1999b) Diaphyseal cross-sectional geometry of Near Eastern Middle Palaeolithic humans: the tibia. Journal of Archaeological Science, 26: 1289-1300.

Trinkaus E. and Ruff C. (1989) Diaphyseal cross-sectional morphology and biomechanics of the Fond-de-Forêt 1 femur and the Spy 2 femur and tibia. Bulletin de la Société royale belge d'Anthropologie et de Préhistoire, 100: 33-42.

Trinkaus E. and Ruff C. (1996) Early modern human remains from eastern Asia: the Yamashita-cho 1 immature postcrania. Journal of Human Evolution, 30: 299-314.

Trinkaus E., Churchill S.E., and Ruff C.B. (1994) Postcranial robusticity in Homo, 2: humeral bilateral asymmetry and bone plasticity. American Journal of Physical Anthropology, 93: 1-34.

Trinkaus E., Ruff C.B., Churchill S.E., and Vandermeersch B. (1998) Locomotion and body proportions of the Saint-Césaire 1 Châtelperonian Neandertal. Proceedings of National Academy of Sciences of the United States of America, 95: 58365840 .

Trinkaus E., Churchill S.E., Ruff C.B., and Vandermeersch B. (1999a) Long bone shaft robusticity and body proportions of 
the Saint-Césaire 1 Châtelperonian Neanderthal. Journal of Archaeological Science, 26: 753-773.

Trinkaus E., Jelínek J., and Pettitt P.B. (1999b) Human remains from the Moravian Gravettian: the Dolní Věstonice 35 femoral diaphysis. Anthropologie, 37: 167-175.

Trinkaus E., Ruff C.B., and Conroy G.C. (1999c) The anomalous archaic Homo femur from Berg Aukas, Namibia: a biome- chanical assessment. American Journal of Physical Anthropology, 110: 379-391.

Trinkaus E., Stringer C.B., Ruff C.B., Hennessy R.J., Roberts M.B., and Parfitt S.A. (1999d) Diaphyseal cross-sectional geometry of the Boxgrove 1 Middle Pleistocene human tibia. Journal of Human Evolution, 37: 1-25. 